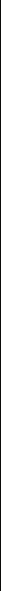

\title{
Estudio histórico y arqueométrico de dos vidrieras de la Catedral de Astorga
}

\author{
María Pilar Alonso Abad, Javier Peña Poza, Fernando Agua Martínez, Francisco Capel del Águila, \\ Manuel García Heras, María Ángeles Villegas
}

\begin{abstract}
Resumen Se estudian las vidrieras de la Catedral de Astorga a partir de dos ejemplos representativos: la Aparición de Jesús resucitado a la Virgen María y el Apóstol San Simón (ss. XVI-XVIII). Se realizó su estudio histórico-artístico y el arqueométrico de una selección de fragmentos de vidrio, con el fin de obtener información sobre su tecnología de producción. El estudio arqueométrico consistió en la determinación de la composición química de los vidrios, la caracterización de sus cromóforos y el estudio de las grisallas. Se determinaron distintos tipos de vidrio, lo que permitió establecer su posible cronología, y diversos cromóforos y grisallas de sombreado y de contorno. El análisis crítico de los datos histórico-artísticos y los arqueométricos puso de manifiesto convergencias y divergencias de datación así como restauraciones anteriores que ubicaron fragmentos en posiciones inadecuadas.
\end{abstract}

Palabras clave: vidrieras, Catedral de Astorga, arqueometría, conservación, cromóforos, grisallas

\section{Historical and archeometric study of two stained-glass windows of the Astorga Cathedral}

Abstract: The stained glass windows of the Astorga Cathedral have been studied from two representative examples: the windows of the Aparición de Jesús resucitado a la Virgen María and the Apóstol San Simón (16 ${ }^{\text {th }}-18^{\text {th }}$ centuries A.D.). The historic and artistic study of such stained glass windows was accomplished and a selection of glass fragments was used to undertake the archaeometric study in order to obtain information on their production technology. Chemical composition of glasses, chromophores characterization and study of grisailles contributed to the archaeometric objectives. Different types of glasses, chromophores and grisailles were determined, which allowed the establishment of their possible chronology. Critical analysis of historical, artistic and archaeometric data demonstrated both convergences and divergences on chronology of glasses as well as the inadequate reusing of glass fragments during past restorations.

Keyword: stained glass windows, Astorga Cathedral, archaeometry, conservation, chromophores, grisailles

\section{Estudo histórico e arqueométrico de dois vitrais da Catedral de Astorga}

Resumo: Estudaram-se os vitrais da Catedral de Astorga a partir de dois exemplos representativos: a Aparição de Jesus Ressuscitado à Virgem Maria e o Apóstolo São Simão (séculos XVI-XVIII). Realizou-se o estudo histórico-artístico e arqueométrico de uma seleção de fragmentos de vidro, a fim de se obterem informações sobre a sua tecnologia de produção. $O$ estudo arqueométrico consistiu na determinação da composição química dos vidros, na caracterização dos seus cromóforos e no estudo das grisalhas. Foram determinados distintos tipos de vidro, o que permitiu estabelecer a sua possível cronologia, e diversos cromóforos e grisalhas de sombreado e contorno. A análise crítica dos dados histórico-artísticos e dos arqueométricos revelou convergências e divergências de datação assim como restauros anteriores de fragmentos em posições inadequadas.

Palavras-chave: vitrais, Catedral de Astorga, arqueometria, conservação, cromóforos, grisalhas 


\section{Introducción}

El patrimonio vidriero conservado en la Catedral de Astorga es un ejemplo de convivencia de diversos lenguajes de la vidriera histórico-artística (Velado Graña 1994). Su restauración se ha acometido en distintas intervenciones (García Paniagua 1997, 2000, 2001, 2003), y la correspondiente a las vidrieras se inició en 1995. Con ella se han recuperado algunos vitrales históricos, se han creado otros nuevos (Roselló Olivares 1996; Iturgáiz Ciriza 2000; Alonso Abad 2004) y se ha devuelto la luminosidad que existió en origen. Esta tarea ha sido complicada ya que, además del comprensible deterioro de la mayoría de las vidrieras debido al paso del tiempo, se daban circunstancias especiales de ventanales tapiados o cegados, vidrieras con paneles enteros o buena parte de fragmentos de vidrio incoloro [figura 1] y otras con fragmentos coloreados y con capas pictóricas parcialmente reconocibles ubicados en posiciones aleatorias que alteraban la lectura iconográfica de conjunto. Estos desajustes, sin duda debidos a intervenciones anteriores realizadas por no profesionales y probablemente bajo la presión de la urgencia de cubrir huecos en los vanos, perjudicaron seriamente la conservación integral de las vidrieras, su lectura iconográfica y el aspecto lumínico del interior de la catedral. El estudio riguroso histórico-artístico y el análisis de varias muestras tomadas de dos conjuntos han ayudado a determinar y constatar la autoría, cronología y naturaleza de los materiales. Los primeros estudios estilísticos, formales e iconográficos, que evidenciaban las manos de los maestros vidrieros que ejecutaron los dos conjuntos objeto de estudio, así como la calidad de sus materiales, se han podido corroborar con los análisis arqueométricos de muestras significativas de la época de factura original y de otras posteriores correspondientes a momentos de alteración y/o restauración. Asimismo, con este estudio interdisciplinar se ha podido constatar la diferencia formal, estilística y de calidad de material empleada en los diferentes conjuntos vidrieros. Una vez restauradas las vidrieras el resultado que ofrece el conjunto es el de una pacífica convivencia entre las históricas y las contemporáneas.

\section{Características históricas y artísticas de las vidrieras estudiadas}

\section{— La vidriera del Apóstol San Simón}

Muy notable por su valor artístico, histórico, estético y técnico, es el elenco de vidrieras del s. XVI de estilo renacentista y manierista. Pese a que se han conservado parcialmente y con ciertas alteraciones en su ubicación e iconografía, son un testimonio importante de un arte que en Europa entraba en desuso y en el olvido técnico de su ejecución, pero que en la Península Ibérica supuso

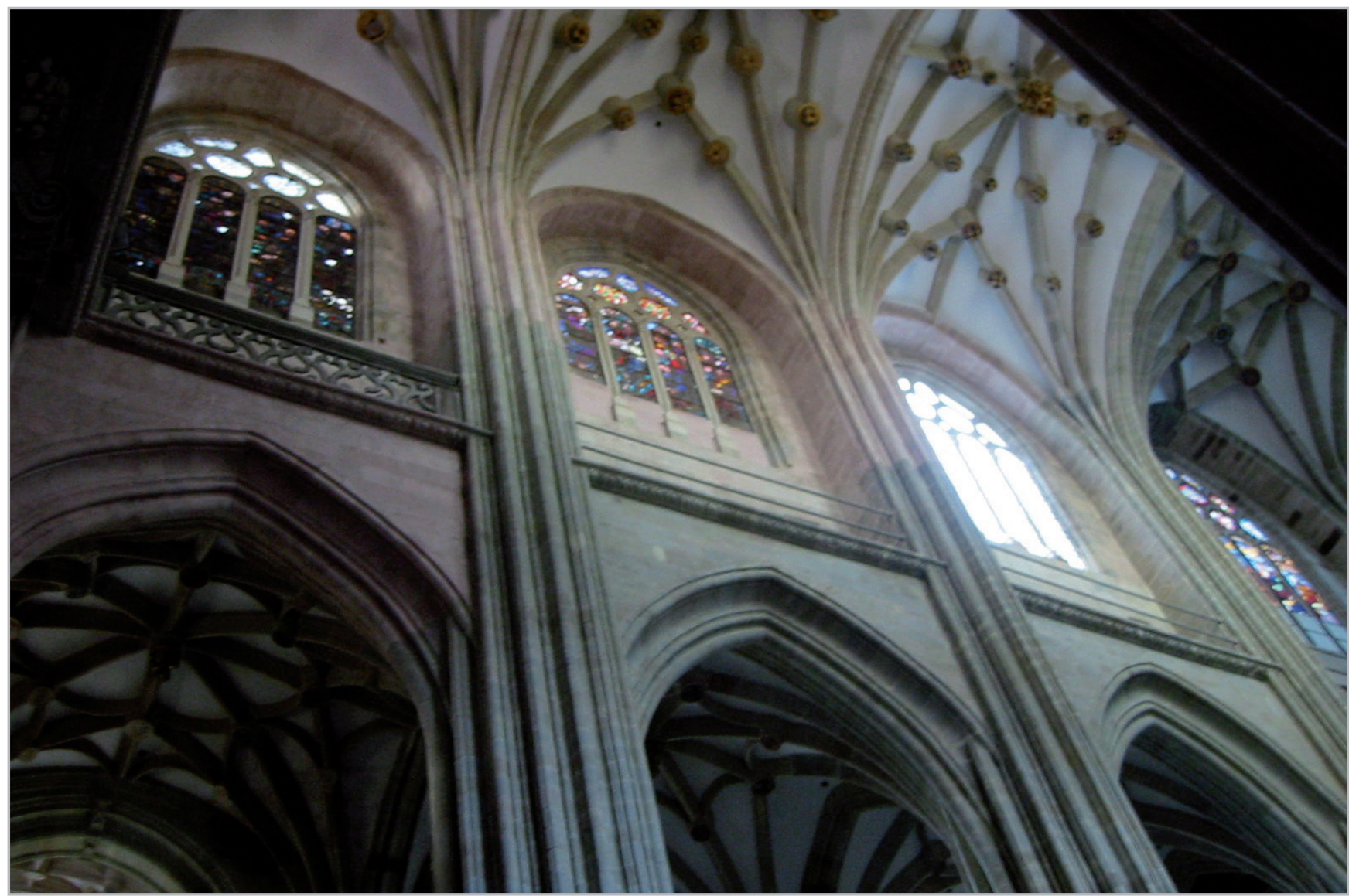

Figura 1.- Vidrieras de la Catedral de Astorga en febrero de 2004 mostrando paneles cegados y otros con vidrios incoloros. 
uno de los periodos más brillantes. La instalación de las primeras vidrieras en la seo se realizó en la década de los años treinta del s. XVI y en torno a los años centrales de la centuria se creó el conjunto más relevante, cuya calidad las hizo merecedoras de estar entre las páginas más brillantes de la historia vidriera española (Nieto Alcaide 1970). En ese momento el Renacimiento se implantaba definitivamente en los centros vidrieros del país, coincidiendo con su máximo esplendor en la Península Ibérica. En la seo confluyeron los lenguajes flamenco y clásico-romanista de manos de maestros vidrieros como Arnao de Vergara y Rodrigo de Herreras. Ellos acreditan el dominio técnico y formal adquirido por una profunda formación teóricopráctica en el arte de la vidriera.

En junio de 2008 culminaba la restauración de la fachada sur de la seo y se ultimaba la recuperación de las vidrieras localizadas en este paramento. Entre ellas dos de las más notables son las llamadas de La Circuncisión y la serie de Santos, entre la que se halla la vidriera del Apóstol S. Simón (ventanal s-X) (Iturgáiz Ciriza 2000). En el tercer tramo de la nave sur se localiza dicho ventanal que se estructura en tres lancetas de remate semicircular, de 7 paneles la central y de 9 las dos laterales, y un óculo superior. Iconográficamente presenta una composición que no es la original, pues se han reintegrado vidrieras de diferentes épocas y de maestros de calidad técnica desigual, y para emplazamientos distintos. Así, la imagen de S. Simón ubicada en la lanceta central, convive con los Cuatro Evangelistas realizados al principio del s. XVIII, que lo flanquean en las lancetas laterales, y con vestigios eclécticos del s. XIX en el óculo superior.

La mayor calidad de este conjunto es la obra de S. Simón que fue realizada por Arnao de Vergara en 1548, como reza la cartela del registro inferior, en su etapa de madurez quizá para la serie de santos de la capilla mayor, donde se descubrió su anagrama (AV) (Nieto Alcaide 1998). Era hijo de Arnao de Flandes el Viejo, introductor del estilo flamenco en la Península Ibérica (Nieto Alcaide 1970, 1974, 1998; La Cartuja de Miraflores 2007; Alonso Abad 2016), en cuyo taller burgalés se formó junto a su hermano Arnao de Flandes. A ellos se debe la evolución desde las pervivencias flamencas al romanismo italiano. Arnao de Vergara ejemplifica la inflexión y la renovación: aunque nunca abandonó algunos rasgos flamenquizantes, asimiló e implantó el Renacimiento, pues recibió su primera formación en el taller paterno, pero en el ambiente renacentista de Burgos. Esto se evidencia en recursos como la disposición medieval de una figura monumental inscrita en arquitecturas de enmarcamientos renacentistas, engalanadas con colgaduras y elementos decorativos aislados. Así, no define un espacio con perspectiva, sino que dispone elementos decorativos en una estructura tradicional medieval de imágenes cobijadas bajo un templete o dosel.

Técnicamente demuestra el dominio del modelado, del dibujo, del sombreado y la definición de claroscuros muy cercanos a la pintura, de la aplicación de la grisalla con un punteado fino para las representaciones del volumen y del empleo de colores de la gama perfectamente logrados, así como la utilización de vidrios de mayores dimensiones y más claros que los de tradición medieval. Los colores responden a la paleta habitual de esta época (rojo, azul, amarillo, verde, violeta y blanco), enriquecida con aplicaciones de amarillo de plata. Probablemente esta vidriera fue creada en colaboración encomendando algunos detalles como los elementos arquitectónicos y decorativos a los talleres familiares asentados en Toledo y muy especialmente en Sevilla, donde su hermano Arnao de Flandes estaba desarrollando series análogas (Nieto Alcaide 1998).

A ambos lados, en sendas lancetas, se reintegraron las imágenes de los Cuatro Evangelistas. Se presentan con corrección iconográfica: en su figura humana redactando su Evangelio con una pluma (S. Marcos y S. Lucas) o señalando un pasaje del mismo (S. Mateo) y acompañados de sus de atributos personales. La composición es idéntica en todos: el panel inferior contiene la peana y los animales, los dos superiores las figuras y el cuarto un enmarcamiento arquitectónico clasicista. Sebastián Pérez, inclinado al oficio de pintor y activo en la seo a finales del s. XVII y primeros del XVIII, fue quien ejecutó estas obras y probablemente también restauró la lanceta de S. Simón. Difiere del anterior maestro estilística y técnicamente, como se confirma en el corte básico del vidrio, su emplomado, la pintura aplicada en gruesas capas de grisalla o en la cocción excesiva en horno (Proyecto de restauración 2009).

El óculo superior está dividido en 4 sectores circulares y cerrado por una reintegración de piezas procedentes de otros ventanales. Lo constituyen imágenes zoomorfas (dos leones rampantes en los registros superiores y el león de $\mathrm{S}$. Marcos sobre el que se despliega una filacteria en el panel inferior izquierdo) y otra imagen figurativa con filacteria de inexacta identificación por la reutilización y adaptación del calibre de los vidrios. Probablemente esta obra se efectuó en alguna de las labores de mantenimiento a partir del s. XVIII. Así pues, el ventanal actual es el resultado de múltiples intervenciones parciales de distintas épocas. Sin embargo, su alterada composición encierra un notable valor artístico y técnico por cuanto de vidriera histórica conserva.

Los proyectos de restauración planteados en mayo de 2008 contemplaban los tramos centrales de la fachada sur del templo. El taller burgalés de Vidrieras Barrio restauró el ventanal del Apóstol S. Simón, concluyendo en julio de 2009. Una primera identificación de las patologías (Proyecto de restauración 2009) verificó el estado del vano, su instalación y protección, y aconsejó sustituir las barras estructurales de hierro por otras de acero inoxidable. Posteriormente se detectaron otras deficiencias y efectos degradantes, producidos por deterioros físicos de los elementos de sujeción (oxidación avanzada de armaduras metálicas y movimientos de la fábrica), pandeamientos de 
los paneles, descomposición formal de la vidriera, fisuras y fracturas en abundantes piezas de vidrio, desprendimientos de grisallas, aberturas en el emplomado y sus soldaduras, así como importantes lagunas (faltas de fragmentos de vidrios). La diversidad material y cronológica fue causa de la inestabilidad química, produciendo corrosión en los vidrios, pérdida de adherencia de las grisallas, de capas de pintura y de trazos de refuerzo aplicados por la cara exterior, así como desarrollo de microorganismos en la cara interior de los vidrios. En la restauración se reintegraron piezas de otros ventanales. Se eliminaron anteriores masillas, morteros, fragmentos de vidrio industrial y materiales adheridos con siliconas. Asimismo, se procedió a la consolidación de elementos constructivos, red de emplomado y vidrios fracturados o con fisuras, a la limpieza mecánica y química, al refijado de grisallas, al control de microorganismos, la reintegración de lagunas y la reinstalación sobre estructuras metálicas inoxidables (Proyecto de restauración 2008).

\section{- La vidriera de la Aparición de Jesús resucitado a la Virgen María}

El conjunto vidriero de la seo empezó a asentarse en el último tercio del s. XVI, cuando ya estaban avanzadas las obras arquitectónicas de mano de talleres leoneses (Nieto Alcaide 1970). El programa se completó durante el s. XVII en algunos ventanales de la cabecera, naves y algunas capillas. A partir del s. XVII, fueron personas ajenas al oficio quienes asumieron el mantenimiento y conservación de las vidrieras preexistentes.

A principios del s. XVIII se creó un programa vidriero para la Capilla de la Virgen Milagrosa, levantada en la Torre Norte. Este conjunto es relevante por su interés históricoestético y técnico, pues representa los valores de creación de vidrieras en un momento de escasa utilización de ésta. En esta capilla se abren dos ventanales en el muro oeste. Son de una única lanceta de remate semicircular que está organizada en 7 paneles. Iconográficamente se dispone un único eje temático: las Apariciones de Jesús Resucitado a las mujeres y los discípulos. Los pasajes escogidos fueron la Aparición a su madre, la Virgen María (ventanal n-XIV) y a María Magdalena (ventanal n-XIII).

La obra se encomendó en torno a 1708 a Sebastián Pérez, a quien también se deben otras tareas en las vidrieras de la seo, como el cierre de algunos ventanales de la nave central con obra nueva y ciertas labores de mantenimiento de vitrales preexistentes (Velado Graña 1991). Cabe suponer que su principal actividad profesional fuera la de pintor, más que vidriero, según se observa del tratamiento de los materiales o las características técnicas de ejecución vidriera; no es de extrañar que encontrara dificultades en la elaboración. Así se evidencia en rasgos como el corte básico del vidrio, la aplicación de la grisalla mediante una capa gruesa (Proyecto de restauración 2008), la pintura al fuego sobre vidrio, una cocción irregular, así como la utilización de un emplomado sencillo. Empleaba la paleta de color propia del s. XVIII (rojo, azul, amarillo, verde y violeta) que se diferencia de las coloraciones renacentistas por el abuso de colores fuertes y la resultante falta de blancos y graduaciones de amarillo de plata sobre vidrios base.

El proceso de mantenimiento de la vidriera ha sido complejo. En las tres centurias posteriores se sucedieron diferentes tareas de limpieza, consolidación de estructuras y piezas dañadas, además de una recomposición de lagunas de vidrios fragmentados o incluso desaparecidos (en ocasiones de origen industrial), sustitución de piezas con otras procedentes de otros ventanales, etc., hasta la definitiva retirada de los dos registros inferiores del ventanal y su tapiado posterior con ladrillos. Estas circunstancias han derivado en una alteración lumínica, cromática y de la lectura iconográfica, aparte de la desaparición completa de los registros inferiores. Pero se han podido reinstalar algunos vidrios custodiados en cajas almacenadas en dependencias de la catedral (cajón de vidriero [1]), y reintegrar los dos paneles inferiores con obra nueva, en un lenguaje abstracto, adecuándose éste a la figuración, la plástica y el cromatismo de los cinco registros superiores. De este modo se guardan las proporciones y la distribución del color, sugiriendo distintos planos con los trazos de grisalla y las manchas de color de los vidrios. El resultado ha sido la restauración integral de las funciones de los ventanales y el cromatismo e intensidad lumínica que muy probablemente tuvieron en origen. Esta misma convivencia de vidriera histórica y actual se observa en el óculo del paramento Sur de la capilla de S. Juan Bautista (1996), en el óculo de la nave norte llamado Jubileo 2000 (1999) y las restantes vidrieras figurativas de la misma nave, así como en los dos óculos de la fachada occidental (2001).

\section{Estudio arqueométrico}

\section{-Muestras de vidrios}

A partir de los fragmentos de vidrio disponibles tras la restauración de las vidrieras de la Aparición de Jesús resucitado a la Virgen María y del Apóstol San Simón, sin valor para su reposición u otro aprovechamiento de interés histórico o museístico, se realizó una selección de 13 muestras representativas cuya descripción se recoge en la tabla 1.

Dicha selección se llevó a cabo con el criterio de disponer de la mayor variedad posible de coloraciones, así como de diversas zonas concretas de procedencia de cada una de las vidrieras estudiadas [figura 2]. También se tuvieron en cuenta la presencia de grisallas (pinturas vitrificables) y las posibles ubicaciones erróneas o reutilizaciones de los fragmentos de vidrio en anteriores trabajos de mantenimiento y restauración. Por todo ello, el conjunto seleccionado de muestras se considera suficientemente representativo de las vidrieras que se estudian. 
Tabla 1.- Selección de muestras de vidrio estudiadas procedentes de las vidrieras objeto de estudio de la Catedral de Astorga.

\begin{tabular}{|c|c|c|c|c|}
\hline Muestra & Referencia & Imagen & Aspecto & $\begin{array}{l}\text { Espesor } \\
\text { (mm) }\end{array}$ \\
\hline 1 & CA-S-X-2-ca & & Verde intenso, sin burbujas & 2,6 \\
\hline 2 & CA-S-X-B-5 & & Azul intenso, sin burbujas & 2,3 \\
\hline 3 & CA-S-X-A-5 & & $\begin{array}{l}\text { Amarillo verdoso, algunas burbujas, } \\
\text { grisalla, depósitos de suciedad en la } \\
\text { superficie }\end{array}$ & 3,6 \\
\hline 4 & $\begin{array}{l}C A-S-X-4-A B- \\
a\end{array}$ & & Azul claro, abundantes burbujas & 2,8 \\
\hline 5 & $\begin{array}{l}\text { CA-S-X-2-AB- } \\
\text { b }\end{array}$ & & Incoloro, sin burbujas, grisalla & 2,2 \\
\hline 6 & $C A-S-X-2-A B$ & & Verde, escasas burbujas, grisalla & 2,0 \\
\hline 7 & CA-S-X-A-2 & & Lila, escasas burbujas & 2,1 \\
\hline 8 & CA-n-XIV-7 & & $\begin{array}{l}\text { Turquesa, algunas burbujas, grisalla, } \\
\text { depósitos de suciedad en la superficie }\end{array}$ & 2,2 \\
\hline 9 & CA-n-XIV-4a & & $\begin{array}{l}\text { Lila pálido, algunas burbujas, grisalla, } \\
\text { depósitos de suciedad en la superficie }\end{array}$ & 2,3 \\
\hline 10 & CA-n-XIV-4-b & & Ámbar, escasas burbujas, grisalla & 2,3 \\
\hline 11 & CA-S-X-C-3 & & Lila, muchas burbujas, grisalla & 4,3 \\
\hline 12 & CA-S-X-A-8 & & Lila intenso, escasas burbujas & 4,4 \\
\hline 13 & CA-S-X-B-6 & & Azul intenso, sin burbujas & 2,2 \\
\hline
\end{tabular}



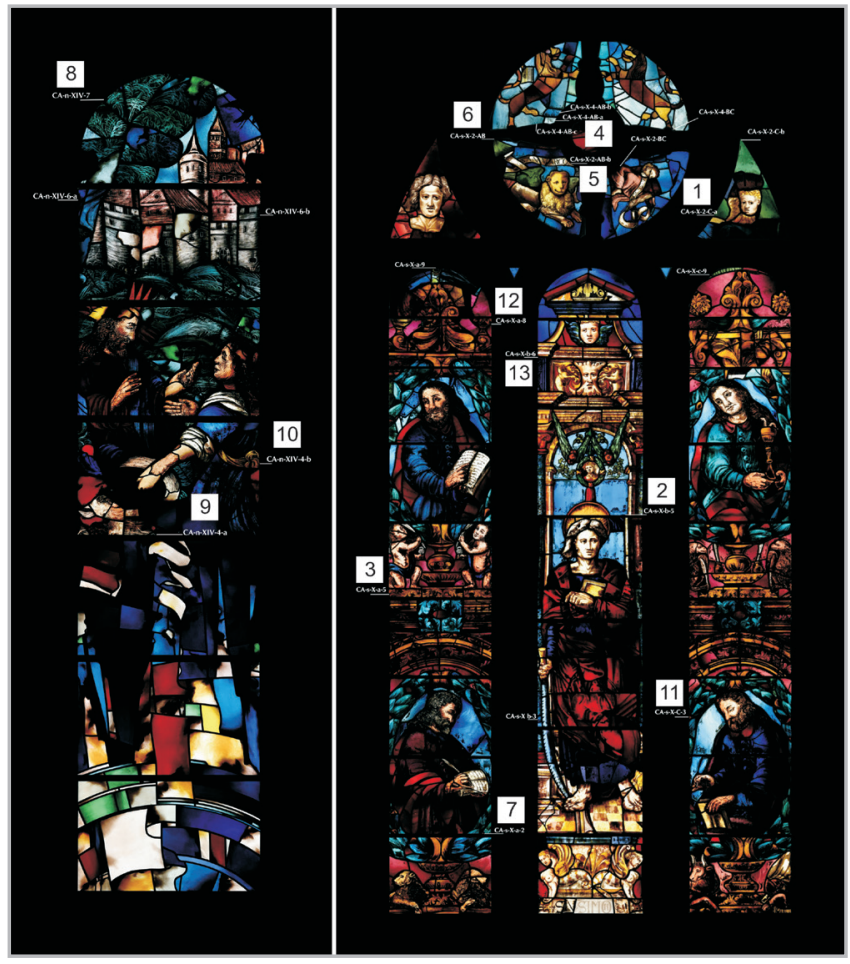

Figura 2.- Izquierda: Vidriera de la Aparición de Jesús resucitado a la Virgen María. Derecha: Vidriera del Apóstol San Simón. Los números indican la posición de las muestras de vidrio seleccionadas para su estudio.

\section{Técnicas de caracterización}

Las características macroscópicas de las muestras, tanto de los vidrios como de sus grisallas, se observaron con una lupa binocular Motic SMZ 168, provista con una cámara digital Moticam 2500. Los análisis químicos de los vidrios se efectuaron mediante espectrometría de fluorescencia de rayos $X(F R X)$ con un equipo PANalytical MagicX (PW-2424), provisto de un tubo de ánodo de rodio (Super Sharp) y generador de 2,4 kW. Las determinaciones analíticas se efectuaron empleando la curva de análisis semicuantitativo $\mathrm{IQ}^{+}$, analizando la muestra preparada en perla. Las perlas se obtuvieron por fusión a $1050^{\circ} \mathrm{C}$ de una mezcla homogénea de 0,3 $\mathrm{g}$ de la muestra en polvo con tamaño de grano inferior a $75 \mu \mathrm{m}$, con $5,5 \mathrm{~g}$ de $\mathrm{Li}_{2} \mathrm{~B}_{4} \mathrm{O}_{7}$. Se empleó una perladora Perl'X3 de Philips y crisol de platino-oro. Los cromóforos responsables del color de los distintos vidrios se detectaron por espectrofotometría UV-Vis-IRP en el intervalo de longitud de onda de 300 a $1100 \mathrm{~nm}$ con un equipo Ocean Optics modelo HR 4000 CG en modo de absorbancia. Las muestras de vidrio se adelgazaron por desbastado y pulido hasta un espesor planoparalelo de $1 \mathrm{~mm}$ y finalmente se pulieron a espejo por ambas caras con una suspensión acuosa de óxido de cerio. La microestructura y el espesor de las grisallas de las muestras de vidrio que presentaban esta decoración se observaron por microscopía electrónica de barrido de emisión de campo (MEBEC), con un equipo de cátodo frío Hitachi S-4800, trabajando con tensiones de aceleración de $15 \mathrm{kV}$. Los microanálisis de espectrometría de dispersión de energías de rayos $X$ (EDS) se realizaron con un sistema acoplado al microscopio Oxford X-Max de 20 $\mathrm{mm}^{2}$ con resolución de 125 eV ( $\mathrm{Mn} \mathrm{Ka}$ ). Previamente las muestras se recubrieron con carbono como medio conductor mediante vaporización en un equipo JEOL JEE4b. Los análisis mediante DRX se realizaron con un difractómetro de polvo Bruker D8 Advance, utilizando la radiación Ka del cobre $(1,54056 \AA$ ) y condiciones de trabajo de $45 \mathrm{kV}$ de tensión y de $40 \mathrm{~mA}$ de intensidad. Los difractogramas se registraron entre $2 \theta=5-60^{\circ}$, con un paso de ángulo de $0,03^{\circ}$ y un tiempo por paso de 2 s. Se empleó el método de polvo (diámetro inferior a $30 \mu \mathrm{m}$ ) con muestra obtenida de la superficie de las muestras.

\section{Resultados y discusión}

\section{-Características macroscópicas}

Como se aprecia en la tabla 1 la mayoría de las muestras presentan burbujas en cantidad y tamaño variable, lo que puede ser compatible con el proceso de fabricación de vidrio plano por medio de manchones y/o de cibas de vidrio soplado. El espesor de las muestras oscila entre 2,0 mm y 4,4 mm, no observándose correlación alguna entre dicho espesor y sus coloraciones. Las grisallas presentan un aspecto compacto y tonos que varían del rojizo al marrón y al negro [figura 3]. En las grisallas de las muestras 3, 8 y 9 se observa una capa de suciedad de pequeño espesor pero firmemente adherida a la grisalla.
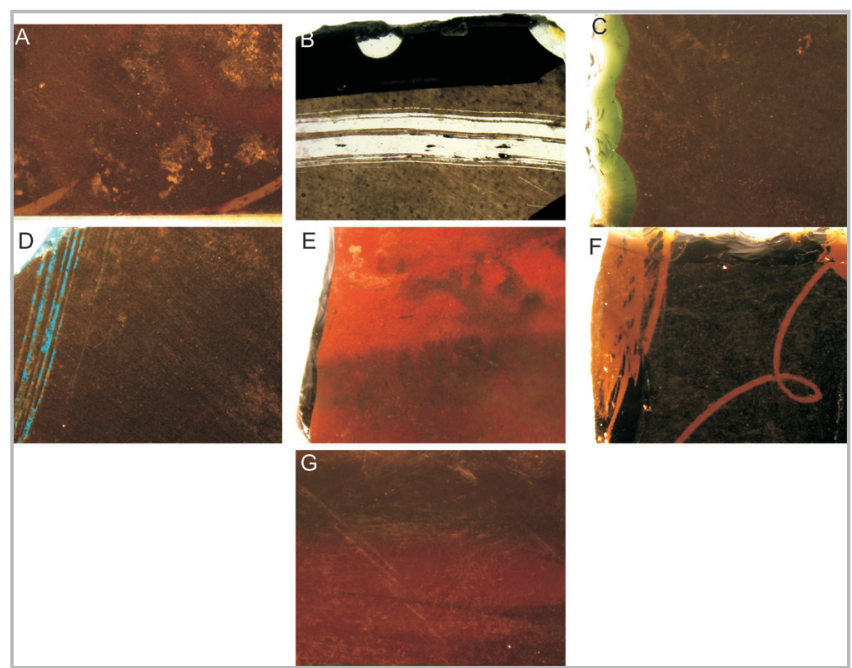

Figura 3.- Imágenes de lupa binocular de las grisallas: A) Muestra 3, B) Muestra 5, C) Muestra 6, D) Muestra 8, E) Muestra 9, F) Muestra 10, G) Muestra 11.

\section{- Análisis químicos}

En la tabla 2 se recogen los resultados de los análisis químicos efectuados por FRX. 
Tabla 2.- . Resultados de los análisis químicos de los vidrios (\% en peso) obtenidos por FRX. Los colores que aparecen en las celdas correspondientes a las muestras indican los grupos composicionales asignados tras la caracterización analítica.

\begin{tabular}{|c|c|c|c|c|c|c|c|c|c|c|c|c|c|}
\hline \multirow{3}{*}{$\begin{array}{c}\text { Vidriera } \\
\text { Muestra } \\
\text { Óxido }\end{array}$} & \multirow{2}{*}{\multicolumn{3}{|c|}{$\begin{array}{l}\text { Vidriera de la Aparición } \\
\text { de Jesús resucitado } \\
\text { a la Virgen María s. XVIII }\end{array}$}} & \multicolumn{10}{|c|}{ Vidriera del Apóstol San Simón } \\
\hline & & & & \multicolumn{4}{|c|}{$\begin{array}{l}\text { Lancetas laterales } \\
\text { s. XVIII }\end{array}$} & \multicolumn{2}{|c|}{$\begin{array}{l}\text { Lanceta central } \\
\text { s. XVI }\end{array}$} & \multicolumn{3}{|c|}{$\begin{array}{l}\begin{array}{c}\text { Óculo } \\
\text { (inferior) } \\
\text { s. XVI }\end{array}\end{array}$} & \multirow{2}{*}{$\begin{array}{c}\begin{array}{c}\text { Óculo } \\
\text { (superior) } \\
\text { s. XIX }\end{array} \\
4 \\
4\end{array}$} \\
\hline & 8 & & 10 & 3 & 11 & 12 & 7 & & 13 & & & 6 & \\
\hline $\mathrm{Na}_{2} \mathrm{O}$ &, 11 & 1,06 & 1,98 &, 35 & 0,44 & 0,66 & 3,31 & 46 & 32 & 1,37 & & 4 & \\
\hline $\mathrm{MgO}$ & & & & 3,48 & 3,44 & & & & & 20 & & & \\
\hline $\mathrm{Al}_{2} \mathrm{O}_{3}$ & & & 5,81 & 4,26 & 3,74 & 1,86 & 1,0 & & & 4,23 & 4,04 & 4,12 & 4,07 \\
\hline $\mathrm{SiO}_{2}$ & 64,1 & 59,50 & 57,42 & 60,97 & 61,35 & 65,18 & 58,05 & 58,94 & 56,75 & 57,06 & 57,15 & 58,40 & 59,96 \\
\hline $\mathrm{P}_{2} \mathrm{O}_{5}$ & 024 & 0.30 & 0,31 & 0,29 & 0,30 & 0,22 & 2,36 & 231 & 1,04 & 2,25 & 2,31 & 2,13 & 0,28 \\
\hline $\mathrm{SO}_{3}$ & & & 0,17 & 0,19 & 0,18 & 0,18 & 0,11 & $0,0 /$ & 0,33 & 0,19 & 0,18 & 0,17 & 0,15 \\
\hline $\mathrm{Cl}^{-}$ & & & 0,79 & 0,47 & 0,38 & 0,5 & 0,74 & 0 & & 0,36 & 0,39 & 0,35 & 0,61 \\
\hline $\mathrm{K}_{2} \mathrm{C}$ & & & 6,84 & & 9 , & 7,69 & 11,94 & 6,59 & 3,34 & 6,59 & 7,93 & 6,39 & 8,57 \\
\hline $\mathrm{CaO}$ & & 9 & 11,40 & 9,44 & 9,49 & 8,04 & 11,13 & 20,54 & 17,73 & 20,96 & 21,21 & 19,21 & 9,23 \\
\hline $\mathrm{TiO}_{2}$ & & 0,10 & 0,15 & 0,10 & 0,08 & 0,06 & 0,07 & 0,20 & 0,14 & 0,21 & 0,16 & 0,17 & 0,09 \\
\hline $\mathrm{MnC}$ & & & & & & & & & & & & & 060 \\
\hline $\mathrm{Fe}_{2} \mathrm{C}$ & & & 0 & 0,7 & 0, & & 0 & & 0,4 & 0,7 & 0,79 & 0,85 & 0,5 \\
\hline $\mathrm{CoC}$ & & & & & & & & & & d. & d. & n.d. & n.d. \\
\hline $\mathrm{CuO}$ & & & 0,06 & 0,13 & 0,1 & & & & 0,08 & 1,83 & 0,03 & 2,20 & n.d. \\
\hline $\mathrm{ZnO}$ & 0, & & $\mathrm{n}$. & n.d. & n.d. & & 0,06 & 0,0 & 0,03 & 0,51 & 0,04 & 0,65 & n.d. \\
\hline $\mathrm{As}_{2} \mathrm{O}_{3}$ & n.c. & & & n.d. & n.d. & & n.c & 0,3 & 0,22 & n.d. & n.d. & n.d. & n.d. \\
\hline $\mathrm{SrO}$ & 0,1 & 0,1 & 0,1 & 0,12 & 0,13 & 0,1 & 0,1 & 0,1 & 0 , & 0,09 & 0,09 & 0,08 & 0,13 \\
\hline $\mathrm{BaO}$ & n.d. & n.d. & n.d. & n.d. & n.d. & n.d. & 0,28 & n.d. & 0,50 & n.d. & 0,24 & 0,33 & n.d. \\
\hline $\mathrm{PbO}$ & 0,11 & n.d. & n.d. & n.d. & n.d. & 0,09 & 0,13 & n.d. & n.d. & n.d. & 0,05 & 0,07 & 0,15 \\
\hline
\end{tabular}

n.d.: no detectado.

Todas las muestras de la vidriera de la Aparición de Jesús resucitado a la Virgen María tienen una composición semejante: son vidrios de silicato sódico cálcico con un contenido equilibrado de los óxidos alcalinos (sodio y potasio), y del óxido de calcio. Este resultado es coherente con las composiciones de los vidrios del s. XVIII (Palomar et al. 2010). También son semejantes los porcentajes de los componentes minoritarios, diferenciándose sólo en los contenidos de los óxidos cromóforos responsables del color en cada caso, como se verá más adelante.

En la vidriera del Apóstol San Simón se han determinado diversos tipos de composiciones. Las muestras 3, 11 y 12 de las lancetas laterales se pueden clasificar en el mismo grupo que las muestras de la vidriera de la Aparición de Jesús resucitado a la Virgen María, es decir son vidrios de silicato sódico cálcico compatibles con el s. XVIII. Sin embargo, la muestra 7 de dichas lancetas presenta una composición distinta con contenidos bajos de óxido de sodio y porcentajes relativamente elevados de óxido de magnesio, fósforo y potasio. Por ello no puede encuadrarse en los vidrios comunes del s. XVIII, a pesar de que estaba ubicado en las lancetas laterales. Su composición es similar al tipo 5 medieval según la clasificación de Müller et al. (1994). Las dos muestras de la lanceta central tienen una composición diferente entre sí: la muestra 2 presenta un contenido muy bajo de óxido de sodio, medio de óxido de potasio y muy elevado de óxido de calcio, por lo que se trata de un vidrio de silicato potásico cálcico, que no se alinea con los vidrios de la vidriera de la Aparición de Jesús resucitado a la Virgen María ni con la mayoría de los de las lancetas laterales, sino con las composiciones más frecuentes del s. XVI. La otra muestra de la lanceta central, vidrio 13, posee una composición casi sin óxido de sodio y contenidos muy elevados de óxidos de potasio y calcio, por lo que es de silicato potásico cálcico pero con proporciones diferentes de las del vidrio 2 también de esta lanceta central. Se puede agrupar en el tipo 1 medieval según Müller et al. (1994).

En las tres muestras analizadas de la parte inferior del óculo, vidrios 1,5 y 6 , se determinaron composiciones muy semejantes a las de la muestra 2 de la lanceta central, es decir, corresponden a vidrios de silicato potásico cálcico compatibles con el s. XVI. Finalmente, la muestra 4 de la parte superior del óculo presenta una composición similar a la de las muestras de la vidriera de la Aparición de Jesús resucitado a la Virgen María y de la mayoría de los vidrios estudiados de las lancetas laterales, o sea, de silicato sódico cálcico compatible con los vidrios del $\mathrm{s}$. XVIII. Comparando los resultados analíticos obtenidos y las asignaciones cronológicas de los vidrios atendiendo a aspectos históricos y artísticos, se ha encontrado buena correlación en los vidrios de la vidriera de la Aparición de 
Jesús resucitado a la Virgen María (s. XVIII). Sin embargo, en la vidriera del Apóstol San Simón sólo la mayoría de los vidrios de las lancetas laterales corresponden, como se suponía, al s. XVIII (excepto la muestra 7 cuya composición es de un vidrio medieval). De acuerdo con su composición, el vidrio 13 de la lanceta central podría ser medieval y reutilizado en el s. XVI. Los vidrios del óculo (parte inferior) y uno de la lanceta central (muestra 2) pueden agruparse como vidrios del s. XVI, mientras que la muestra analizada de la parte superior del óculo (vidrio 4) se puede clasificar junto con las del s. XVIII, a pesar de que se suponía del s. XIX. En la tabla 2 los colores de sombreado de las celdas correspondientes a las muestras indican los distintos grupos compositivos propuestos.

El estudio analítico de las aleaciones de plomo utilizadas en los perfiles de la red de emplomado de las vidrieras es importante para la caracterización arqueométrica del conjunto de la vidriera, así como para establecer la posible interacción vidrio-plomo desde el punto de vista de su conservación integral (García Heras et al. 2003, 2004, 2006). Sin embargo, no siempre las muestras de la red de emplomado son accesibles, por no mencionar las restauraciones en las que el emplomado se sustituye parcial o totalmente sin tener en cuenta que los perfiles de plomo son también un material histórico constituyente de las vidrieras, lo mismo que los fragmentos de vidrio coloreado. En el presente estudio no se tuvo acceso a muestras de la red de emplomado, lo que, sin duda, hubiera enriquecido el estudio analítico y su interpretación integrada con los análisis químicos de los vidrios.

\section{-Estudio de los cromóforos}

En la figura 4 se muestran los espectros de absorción UVVis-IRP de los vidrios estudiados que presentan color.

La asignación de las bandas de absorción visible se ha realizado según Fernández Navarro (2003). Los cromóforos de los vidrios 1 y 6 verdes son los iones $\mathrm{Cu}^{2+}$ (banda a $780 \mathrm{~nm}$, azul) y los iones $\mathrm{Fe}^{3+}$ (bandas a 380, 420 y $440 \mathrm{~nm}$, amarillo). En los vidrios 2 y 13 azules los cromóforos son los iones $\mathrm{Co}^{2+}$ (absorción a 530, 595 y $645 \mathrm{~nm}, \mathrm{azul})$, si bien en el vidrio 13 la tonalidad es más apagada por la presencia de iones $\mathrm{Mn}^{3+}$ (banda a $500 \mathrm{~nm}$, violeta). El vidrio 3 verdoso muy claro está coloreado por iones $\mathrm{Cu}^{2+}$ y $\mathrm{Fe}^{3+}$. En el vidrio 4 azul claro los cromóforos son los iones $\mathrm{Mn}^{3+}$ y $\mathrm{Fe}^{3+}$, que se detectan en el análisis químico, así como un pequeñísimo contenido de iones $\mathrm{Co}^{2+}$ cuyo color azul tan intenso enmascara al de los otros cromóforos presentes. El espectro del vidrio 5 incoloro no se registró. Los cromóforos del vidrio 8 azul verdoso son los iones $\mathrm{Cu}^{2+}$ y en menor proporción los iones $\mathrm{Fe}^{3+}$ y $\mathrm{Mn}^{3+}$, que quedan enmascarados por la intensa absorción de los $\mathrm{Cu}^{2+}$. El vidrio 9 ligeramente gris presenta los cromóforos $\mathrm{Mn}^{3+}, \mathrm{Fe}^{3+}$ y $\mathrm{Cu}^{2+}$ en pequeñas cantidades. En el vidrio 10 el principal cromóforo son partículas coloidales de Ag0 (absorción a $400 \mathrm{~nm}$, amarillo), no detectables en el análisis químico, junto con iones $\mathrm{Fe}^{3+}$ que contribuyen al oscurecimiento del tono. Los cromóforos de los vidrios 7 y 12 violetas y del vidrio 11 violeta claro son los iones $\mathrm{Mn}^{3+}$ y $\mathrm{Fe}^{3+}$ en distintas proporciones, lo que da lugar a las diferentes tonalidades de los vidrios.

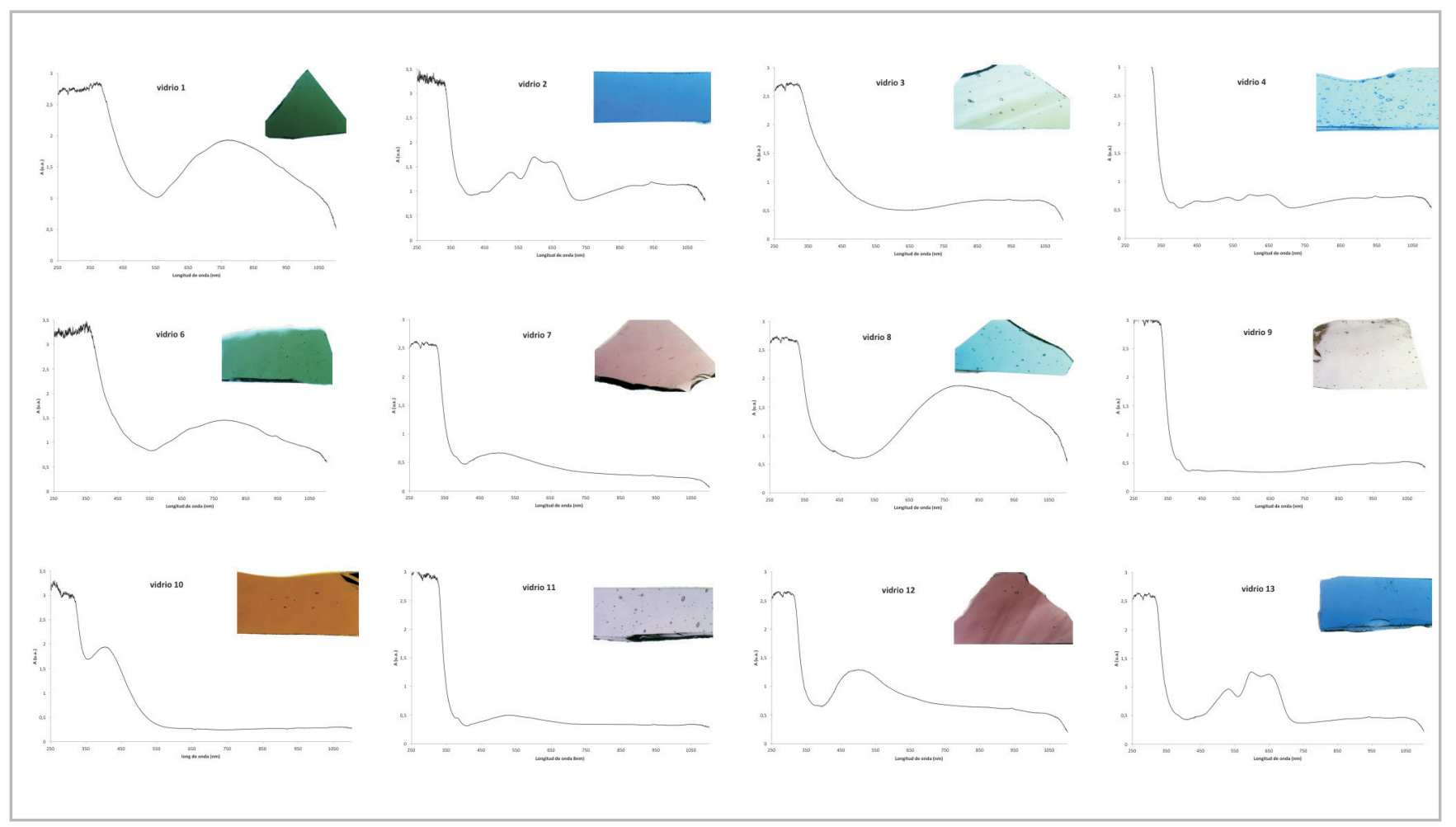

Figura 4.- Espectros de absorción UV-Vis-IRP de las muestras de vidrios coloreados estudiados. 
Teniendo en cuenta esta asignación de cromóforos y los resultados de los análisis químicos realizados [tabla 2], la figura 5 recoge los dos grupos principales de vidrios ordenados según su posible clasificación cronológica.

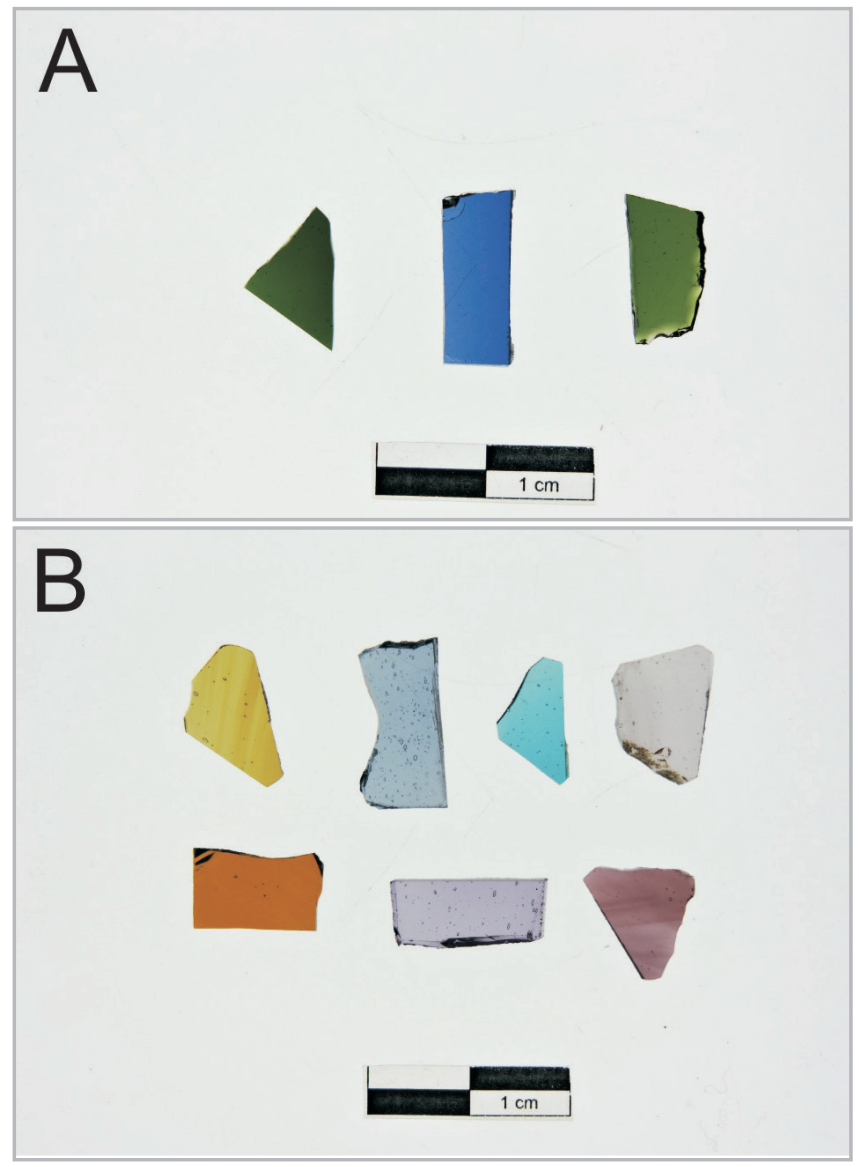

Figura 5.- Principales grupos cromáticos de los vidrios estudiados: A) Atribuidos composicionalmente al s. XVI, B) Atribuidos composicionalmente al s. XVIII.

Como se aprecia, la variedad de colores y sutileza de los tonos de los vidrios de posible cronología del s. XVIII es más variada que la de los vidrios de posible cronología del s. XVI. Este hecho demuestra los avances tecnológicos que la producción de vidrio plano experimentó en dicha época (García Heras et al. 2012), lo que no indica necesariamente que la técnica de la vidriera en el s. XVIII fuera más depurada que en el s. XVI; simplemente hace referencia a los avances técnicos respecto al uso de cromóforos combinados. Efectivamente los vidrios atribuidos al s. XVI poseen un sólo tipo de cromóforo que imparte un color neto e intenso, mientras que los vidrios atribuidos al s. XVIII deben su coloración a dos o tres cromóforos cuya suma cromática da lugar a la variedad de tonos que se observan en la figura 5B.

\section{-Caracterización de las grisallas}

En la figura 6 se observan las micrografías de MEBEC de la sección transversal de una selección representativa de las grisallas objeto de estudio, y en la tabla 3 los resultados de los microanálisis de EDS efectuados en varias zonas de las grisallas.
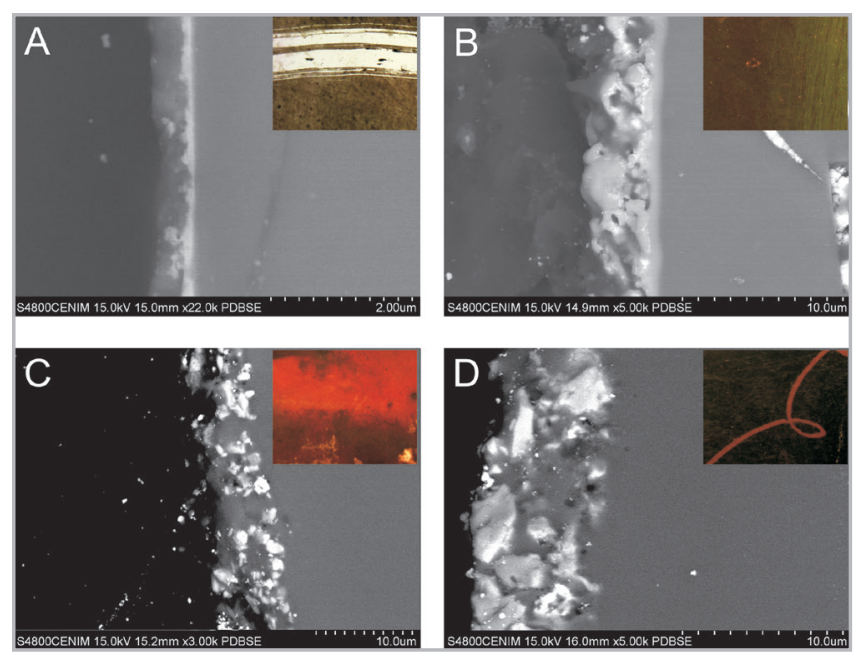

Figura 6.- Micrografías de MEBEC de algunas grisallas representativas estudiadas y resultados de los microanálisis EDS: A) Muestra 5, B) Muestra 6, C) Muestra 9, D) Muestra 10.

La grisalla de sombreado del vidrio 5 (espesor $600 \mathrm{~nm}$ ) [figura 6A] aparece bien densificada al cuerpo de vidrio, ya que presenta una microestructura sin aristas y su intercara con el vidrio es difusa. Su microanálisis indica que está compuesta mayoritariamente de óxidos de silicio, plomo, calcio, fósforo, aluminio y hierro, este último responsable de su color gris. La grisalla de la muestra 6 [figura 6B] tiene las mismas características microestructurales que la anterior, aunque al tratarse de una grisalla de contorno tiene un mayor espesor $(5 \mu \mathrm{m})$, y está compuesta de óxidos de silicio, hierro, plomo, calcio y cobre, actuando como

Tabla 3.- Resultados de los microanálisis EDS efectuados en distintas zonas de la sección trasversal de las grisallas

\begin{tabular}{|c|c|c|c|c|c|c|c|c|c|c|c|}
\hline Muestra & $\mathbf{N a}_{\mathbf{2}} \mathbf{O}$ & $\mathbf{M g O}$ & $\mathbf{A l}_{\mathbf{2}} \mathbf{O}_{\mathbf{3}}$ & $\mathbf{S i O}_{\mathbf{2}}$ & $\mathbf{P}_{\mathbf{2}} \mathbf{O}_{\mathbf{5}}$ & $\mathbf{C l}$ & $\mathbf{K}_{\mathbf{2}} \mathbf{O}$ & $\mathbf{C a O}$ & $\mathbf{F e}_{\mathbf{2}} \mathbf{O}_{\mathbf{3}}$ & $\mathbf{C u O}$ & $\mathbf{P b O}$ \\
\hline $\mathbf{5}$ & 2,0 & n.d. & 9,1 & 29,1 & 11,4 & 1,6 & 3,0 & 13,8 & 6,2 & n.d. & 23,8 \\
\hline $\mathbf{6}$ & 2,2 & n.d. & 2,9 & 35,9 & n.d. & n.d. & 5,0 & 9,8 & 27,5 & 4,4 & 12,3 \\
\hline $\mathbf{9}$ & 4,1 & 1,8 & 2,4 & 25,9 & n.d. & n.d. & 3,0 & 3,5 & 41,4 & 18,0 & n.d. \\
\hline $\mathbf{1 0}$ & 4,1 & 2,0 & 1,6 & 14,4 & n.d. & n.d. & 2,0 & 4,4 & 71,7 & n.d. & n.d. \\
\hline
\end{tabular}


cromóforos el hierro y el cobre que imparten un tono pardo. Sin embargo, en la grisalla de sombreado del vidrio 9 (espesor $6 \mu \mathrm{m}$ ) [figura $6 \mathrm{C}$ ], a pesar de que presenta una intercara difusa con el vidrio que indica buena adherencia, se observan granos con aristas que no han reaccionado completamente durante la densificación térmica. En esta grisalla se ha detectado un contenido muy elevado de óxido de hierro (granos claros con aristas), yóxidos de silicio y cobre. Su color rojizo es debido a los óxidos de hierro y cobre. En la grisalla de contorno de la muestra 10 (espesor $8 \mu \mathrm{m}$ ) [figura 6D] se aprecia la misma microestructura que en la anterior $y$, asimismo, está bien densificada y adherida al vidrio. Contiene una proporción muy elevada de óxido de hierro, responsable de su tono marrón muy oscuro, y óxido de silicio como otro mayoritario. Las grisallas de las muestras 5 y 6 correspondientes a vidrios del s. XVI son de pequeño espesor, están bien densificadas y tienen óxido de plomo en su composición, mientras que las grisallas de las muestras 9 y 10 de muestras de vidrios del s. XVIII son de mayor espesor, no están completamente densificadas, no contienen óxido de plomo en su composición y en cambio tienen una cantidad muy elevada de óxido de hierro.

La capa de suciedad adherida a la superficie de algunas de las grisallas estudiadas se caracterizó mediante DRX. En los correspondientes difractogramas de rayos $\mathrm{X}$ se detectó yeso $\left(\mathrm{CaSO}_{4} \cdot 2 \mathrm{H}_{2} \mathrm{O}\right)$ y lanarkita $\left(\mathrm{Pb}_{2}\left(\mathrm{SO}_{4}\right) \mathrm{O}\right)$, que se pueden atribuir a contaminación procedente de la masilla y de la red de emplomado, respectivamente. No obstante, no se puede descartar que el yeso se haya formado como un producto resultante del ataque químico de los vidrios en una atmósfera contaminada (por ejemplo, de $\mathrm{SO}_{2}$ ) por extracción de los iones $\mathrm{Ca}^{2+}$ de la red vítrea.

\section{Conclusiones}

Desde el punto de vista compositivo, las muestras de la vidriera de la Aparición de Jesús resucitado a la Virgen María tienen una composición química semejante y son vidrios de silicato sódico cálcico de porcentajes equilibrados. Sin embargo, en la vidriera del Apóstol San Simón se han determinado diversos tipos de composiciones: vidrio de silicato potásico cálcico coherente con las composiciones del s. XVI, vidrio de silicato potásico cálcico tipo 1 medieval según Müller et al., vidrio tipo 5 medieval según Müller et al., y vidrio de silicato sódico cálcico de porcentajes equilibrados (como los de la vidriera anterior). El análisis cromático puso de manifiesto que en aquellos vidrios de posible cronología del s. XVI se utilizó un solo cromóforo responsable de las coloraciones netas e intensas que se observan, mientras que en los vidrios de posible cronología del s. XVIII se usaron mezclas de dos o tres cromóforos cuyo efecto dio lugar a tonos intermedios y sutiles. Las grisallas tanto de sombreado como de contorno presentan, en general, buena densificación y adherencia al vidrio base, y se componen principalmente de óxidos de hierro y cobre como colorantes masivos en una base de óxidos de silicio, plomo y calcio. Esto explica los tonos rojizos, pardos y grises que presentan.
El estudio arqueométrico de la presente selección representativa de vidrios de dos vidrieras de la Catedral de Astorga ha puesto de manifiesto su utilidad para confirmar la mayoría de los aspectos cronológicos y estilísticos revelados mediante la investigación histórica. Asimismo, ha permitido conocer la posible cronología de producción de algunos vidrios cuya asignación temporal no era precisa, hecho que confirma, por otro lado, las evidentes mezclas y reutilizaciones de vidrios en las vidrieras estudiadas. La investigación multidisciplinar de las características histórico-artísticas y de los materiales de estas vidrieras ha clarificado muchos aspectos técnicos como la composición y tecnología de producción de los vidrios estudiados, su decoración con capas pictóricas (grisallas), los problemas de conservación desde su creación $y$, cuando menos, ha actualizado el estado de la cuestión sobre unas vidrieras alteradas tanto por la meteorización natural como por las sucesivas intervenciones a que han sido sometidas.

\section{Agradecimientos}

Los autores agradecen a la Comunidad de Madrid y Fondos Estructurales (FSE y FEDER) la financiación del programa Geomateriales 2 ref. S2013/MIT-2914. Asimismo, agradecen el apoyo profesional de TechnoHeritage, Red de Ciencia y Tecnología para la Conservación del Patrimonio Cultural.

M.P.A.A. es miembro de la Unidad Asociada de I+D+i al CSIC "Vidrio y Materiales del Patrimonio Cultural".

\section{Bibliografía}

ALONSO ABAD, Ma P. (2004). "Los nuevos vitrales de la Colegiata de Medina del Campo realizados por artistas vidrieros burgaleses", BIFG, 229 (2): 353-375 (366-372).

ALONSO ABAD, Ma P. (2016). Las Vidrieras de la Catedral de Burgos. Castellón: CSIC.

FERNÁNDEZ NAVARRO, J.M. (2003). El Vidrio. Madrid: Ed. CSIC.

GARCÍA PANIAGUA, A. (2000). "Restauraciones en la Catedral de Astorga (León)", Ars Sacra, 13: 39-46.

GARCÍA PANIAGUA, A. (2001). "Últimas restauraciones en la Catedral de Astorga (León)". En Actas del Congreso Internacional "Restaurar la Memoria", Valladolid: Junta de Castilla y León, 629636.

GARCÍA PANIAGUA, A. (2003). "Últimas restauraciones en la Catedral de Astorga (León)", ROC Maquinaria: Piedras naturales, maquinaria y equipos, 78: 14-18.

GARCíA PANIAGUA, A.; PÉREZ López, F. J. (1997-1998). "Plan Director de la Catedral de Astorga", Ars Sacra, 4/5: 41-46. 
GARCÍA-HERAS, M.; VILLEGAS, M.A.; CANO, E.; CORTÉS, F.; BASTIDAS, J.M. (2003). "Conservation and analytical study of metallic elements from medieval Spanish stained glass windows". En Proc. Archeometallurgy in Europe, Milán (Italia): Editorial Asociación Italiana de Metalurgia, 381-390.

GARCÍA-HERAS, M.; VILLEGAS, M.A.; CANO, E.; CORTÉS PIZANO, F.; BASTIDAS, J.M. (2004)."A conservation assessment on metallic elements from Spanish Medieval stained glass windows", J. Cultural Heritage, 5 (3): 311-317.

GARCÍA-HERAS, M.; VILLEGAS, M.A; CAEN, J.M.A.; DOMINGO, C.; GARCÍA-RAMOS, J.V. (2006). "Patination of historical stained windows lead cames from different European locations", Microchem. J. 83(2): 81-90.

GARCÍA-HERAS, M.; FERNÁNDEZ NAVARRO, J.M.; VILLEGAS, M.A. (2012). Historia del vidrio. Desarrollo formal, tecnológico y científico. Madrid: Ed. Proyecto PIE 200460E594, CSIC.

ITURGÁIZ CIRIZA, D. (OP) (2000). “Restauración de vidrieras de la Catedral de Astorga", Ars Sacra, 13: 95-103.

MÜLLER, W.; TORGE, M.; ADAM, K. (1994). "Ratio of CaO/K2O>2 as evidence of a special Renish type of medieval stained glass", Glastech. Ber. Glass Sci. Technol., 67 (2): 45-48.

NIETO ALCAIDE, V. (1970). La vidriera del Renacimiento en España. Madrid: CSIC.

NIETO ALCAIDE, V. (1974). Arnao de Vergara. Sevilla: Diputación Provincial.

NIETO ALCAIDE, V. (1998). La vidriera española. Ocho siglos de luz, Madrid: Nerea.

PALOMAR, T.; AGUA, F.; GARCÍA-HERAS, M.; CORTÉS, F.; VILLEGAS, M.A. (2010). "Evaluación arqueométrica de vidrios procedentes de vidrieras españolas del s. XVIII". En AR\&PA 2008. Actas (tomo II) del VI Congreso Internacional "Restaurar la Memoria". La gestión del patrimonio, hacia un planteamiento sostenible, Valladolid: Editorial Junta de Castilla y León, Consejería de Cultura y Turismo, 499-508.

Proyecto de Restauración (2008). Burgos: Taller de Vidrieras Barrio.

Proyecto de Restauración (2009). Burgos: Taller de Vidrieras Barrio.

ROSELLÓ OLIVARES, M. (1996). "Restauración de dos vidrieras de la Catedral de Astorga (León)". En Actas del XI Congreso de Conservación y Restauración de Bienes Culturales, Castellón: Diputación Provincial, 901-914.

VELADO GRAÑA, B. (1991). La Catedral de Astorga y su museo. Astorga: Museo de la Catedral de Astorga.

VELADO GRAÑA, B. (1994). "Las vidrieras de la Catedral de Astorga", Amigos de la catedral, 7: 21.

VV.AA., La Cartuja de Miraflores. III. Las Vidrieras (2007). Madrid: Cuadernos de Restauración de Iberdrola, XIII.

\section{Autor/es}

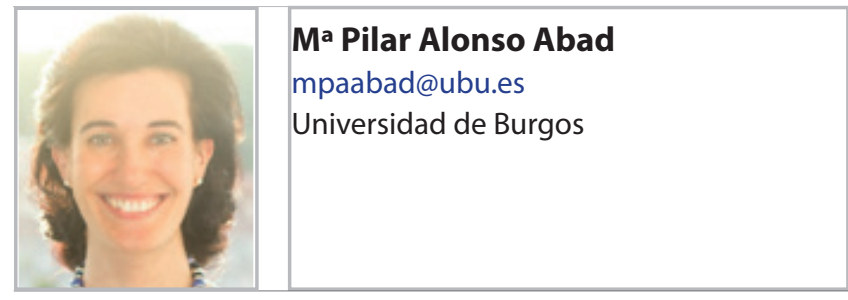

Doctora en Humanidades por la Universidad de Burgos (2003). Profesora del Área de Historia del Arte de la Universidad de Burgos desde 2005. Es Secretaria de la Sección Arte, Arqueometría y Patrimonio de la Sociedad Española de Cerámica y Vidrio desde 2016. Desarrolla una línea de investigación en torno al patrimonio en vidrio y las vidrieras artísticas, y el patrimonio artístico y cultural hispano. Como fruto de sus investigaciones ha sido galardonada con el Primer Premio a la Investigación (2017) del Consejo Social de la Universidad de Burgos, por su libro "Las Vidrieras de la Catedral de Burgos", y también con el Premio Internacional Compostela (2018) por su trayectoria académica e investigadora en el Patrimonio Cultural y la difusión de los valores del Camino de Santiago.

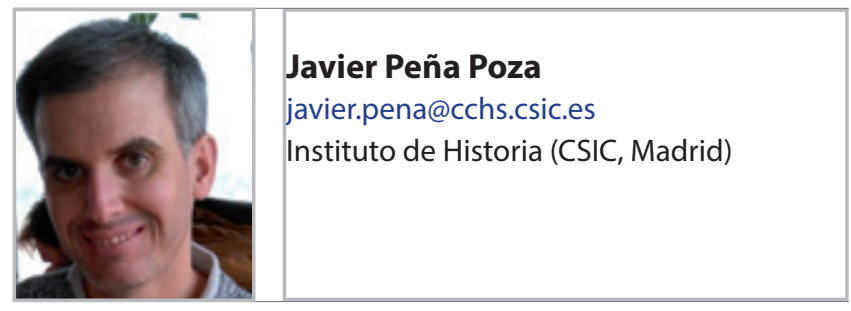

Doctor en Ciencias Químicas por la Universidad Autónoma de Madrid (2014). Investigador contratado en el Instituto de Historia (CSIC, Madrid), desde 2009 hasta 2013 en el Programa Consolider Ingenio TCP-CSD2007-00058; desde marzo de 2015 hasta agosto de 2017 y desde mayo de 2018 hasta la actualidad en el Programa Geomateriales 2 Ref. S2013/MIT-2914 Comunidad de Madrid y Fondos Estructurales de la UE; y desde octubre de 2017 hasta abril de 2018 en el Proyecto del Plan Nacional MAT2015-65445C2-2-R. Sus investigaciones se centran en la aplicación de técnicas de caracterización químico-físicas en materiales inorgánicos y en el desarrollo de estrategias de conservación preventiva mediante sensores ambientales.

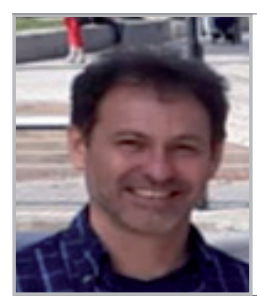

Fernando Agua Martínez

fernando.agua@cchs.csic.es Instituto de Historia (CSIC, Madrid)

Licenciado en Ciencias Químicas por la Universidad de Alcalá (1991). Accedió al Consejo Superior de Investigaciones Científicas en 1992 como ayudante de investigación y desde 2005 a la escala de Titulados Superiores Especializados del CSIC. Perteneció a la plantilla del Instituto de Ciencia de Materiales de Aragón, del Instituto de Cerámica y Vidrio de Madrid y, desde 2007, su 
destino es el Instituto de Historia de Madrid. Sus investigaciones se encuadran en la arqueometría de materiales históricos, así como en el desarrollo de estrategias de conservación curativa y preventiva para los materiales del Patrimonio Cultural.

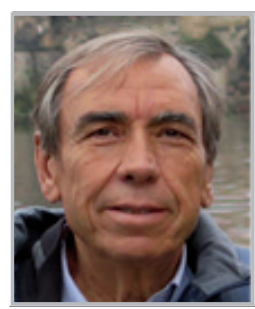

\section{Francisco Capel del Águila}

fcapel@icv.csic.es

Instituto de Cerámica y Vidrio (CSIC, Madrid)

Doctor en Ciencias Químicas por la Universidad Complutense de Madrid y licenciado en Ciencias Sociales por la misma universidad. Fue responsable del Laboratorio de Propiedades Mecánicas del Instituto de Cerámica y Vidrio del CSIC, Madrid. Ha sido vocal y secretario desde 1975 a 1993 del Comité Técnico de Normalización CT 43 de la Asociación Española de Normalización y Certificación AENOR. Expresidente de la Sección Arte, Arquemetría y Patrimonio de la Sociedad Española de Cerámica y Vidrio, de la que es socio de honor. Es coautor del libro"El vidrio en la pintura del Museo Nacional del Prado" que obtuvo el $2^{\circ}$ premio como libro mejor editado en 2012 del Ministerio de Educación, Cultura y Deporte de España..

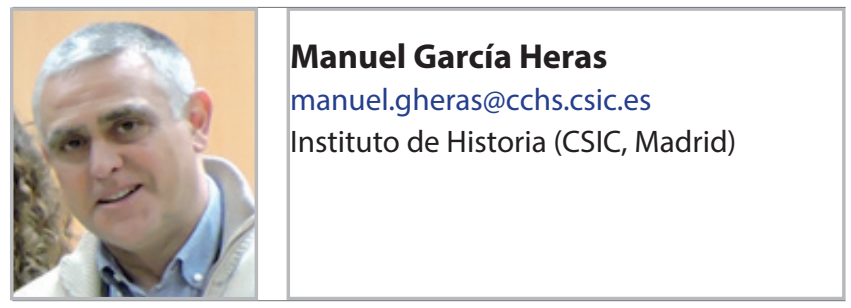

Doctor en Historia con Premio Extraordinario por la Universidad Complutense de Madrid (1997). Entre 1999y 2001 fue investigador postdoctoral Fulbright en la Smithsonian Institution, Washington D.C., EE.UU.; y entre 2002 y 2005 investigador postdoctoral del programa I3P en el Centro Nacional de Investigaciones Metalúrgicas (CSIC, Madrid). Desde 2005 es Científico Titular en el Instituto de Historia (CSIC, Madrid). Sus líneas de investigación se centran en la interacción entre ciencias experimentales e historia, combinando una visión histórica y científica en la aproximación a cuestiones de tecnología y conservación de materiales antiguos. Estas líneas se llevan a cabo principalmente en los campos de la Arqueometría y la conservación del Patrimonio Cultural.

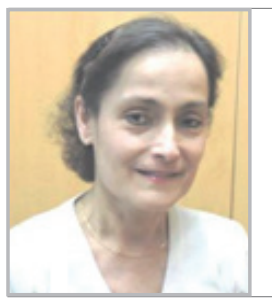

Ma Ángeles Villegas Broncano

mariangeles.villegas@cchs.csic.es Instituto de Historia (CSIC, Madrid)

Doctora en Ciencias Químicas por la Universidad Autónoma de Madrid (1987) y en Arte por la Universidad de Granada (2016),
Profesora de Investigación del CSIC, en el Instituto de Cerámica y Vidrio (1984-2001), Centro Nacional de Investigaciones Metalúrgicas (2001-2007) e Instituto de Historia (desde 2007). Es la responsable de un grupo de investigación sobre materiales del Patrimonio Cultural y presidenta de la Sección Arte, Arqueometría y Patrimonio de la Sociedad Española de Cerámica y Vidrio. Sus líneas de investigación son: Conservación integral (curativa y preventiva) y protección del Patrimonio Cultural; Sensores ambientales y sistemas avanzados de conservación preventiva; Arqueometría de materiales (vidrio, cerámica, metales, aleaciones, capas pictóricas, etc.) . 